serum). From ten to twenty minutes after the sensitized corpuscles have been added the results are read. Where less haemolysis is observed in the tubercle antigen tube than in the syphilitic antigen one the serum is tuberculous, in addition to being luetic. If, on the other hand, the reverse is the state of haemolysis, the probability is that the serum is only specific, and not tuberculous.

\section{Results of Investigation.}

Our investigation deals with the examination of serums trom 104 tuberculons subjects, and 220 controls. Of the tuberculous, in 57 cases tubercle bacilli were found in the sputum, and in 47 they were absent. Altogether 49 of the cases had received tuberculin treatment at one time or another of the disease. The controls consist of 100 positive and 100 negative Wassermann serums, and of 20 serums taken from persons clinically known to be free from tuberculosis. Consideration of space has induced us to give, in lieu of a protocol in extenso, merely a summary of the results arrived at, as set forth in the accompanying tables (III, IV, and V).

TABLE III.-Summary of the General Results.

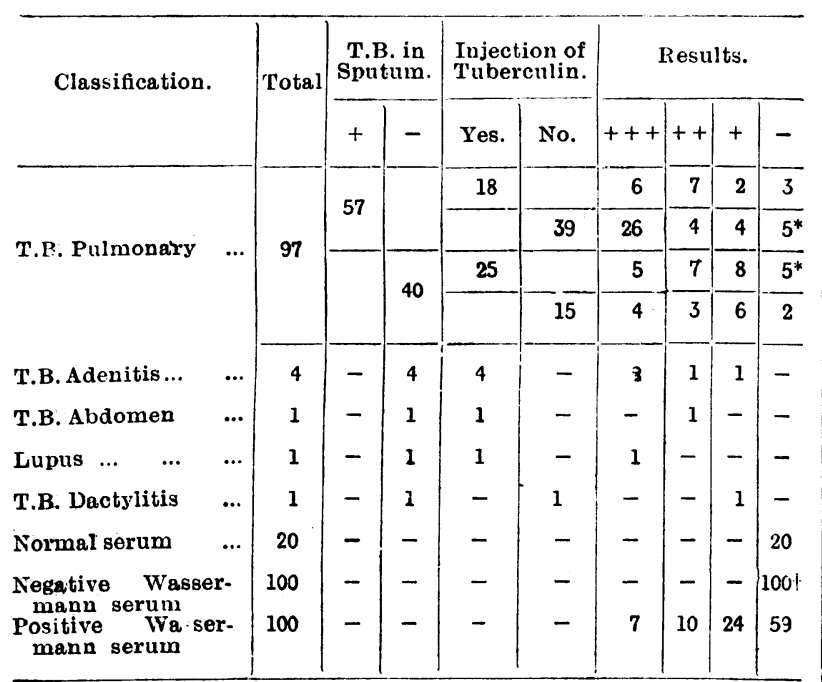

*Inc.uding 1 doubtful each. † Including 3 doubtfuls.

Table IV.-Showing the Percentage of Positives in Tuberculou Cases treated und not treated with Tuberculin, and in Controls.

\begin{tabular}{|c|c|c|c|c|c|c|c|}
\hline & & \multicolumn{3}{|c|}{ Positive Results. } & \multirow{2}{*}{$\begin{array}{l}\text { Negative } \\
\text { Results. }\end{array}$} & \multirow{2}{*}{$\begin{array}{l}\text { Per Cent. } \\
\text { Positive. }\end{array}$} \\
\hline & & & $++t$ & $+t$ & + & & \\
\hline \multicolumn{8}{|l|}{ Tuberculogs cases: } \\
\hline No tuberculin... & ... & $\ldots$ & 30 & 7 & 11 & 7 & 87 \\
\hline Normal serum $\quad \ldots$ & $\cdots$ & $\cdots$ & 一 & 一 & - & 20 & 0 \\
\hline \multirow{2}{*}{\multicolumn{3}{|c|}{ Negative Wassermann serum }} & - & - & - & 100 & 0 \\
\hline & & & 7 & 10 & 24 & 59 & 41 \\
\hline
\end{tabular}

All the positive Wassermann serums which were found to give a positive reaction in the test were further tested with the chloroform differential method, and in every instance the serums after treatment became negative. It may be stated here that this differential test has been applied, besides those cases just mentioned, to 30 specimens made up of known luetic and tuberculous serums, and with no exception all the serums remained positive. It is significant to note in the above tables that the results do not afford evidence of an effect which tuberculin, in the small doses as usually administered, has in the production of antibodies in the circulating blood, as judged by the reaction of the test, nor, it may be mentioned here, have we observed any relation between the strength of the reaction and the extent and severity of the disease. Interpreted according to the rules above formulated, arbitiary though they are, the results yielded may be expressent thus:
TABLE V.

\begin{tabular}{|c|c|c|c|c|c|c|c|}
\hline \multicolumn{6}{|c|}{ Results. } & \multirow{2}{*}{$\frac{\text { Tuberculous. }}{44}$} & \multirow{2}{*}{$\frac{\text { Controls. }}{-}$} \\
\hline Strong positiv & $1+t$ & $\ldots$ & $\ldots$ & $\ldots$ & $\ldots$ & & \\
\hline Moderately str & ng 1 & itiv & $(+t)$ & $\ldots$ & $\ldots$ & 23 & - \\
\hline Weak positive & & $\ldots$ & $\ldots$ & $\ldots$ & $\ldots$ & 22 & - \\
\hline Negative (-) & $\cdots$ & $\cdots$ & $\ldots$ & $\ldots$ & $\ldots$ & 15 & $2: 0$ \\
\hline Total ... & $\cdots$ & $\cdots$ & $\cdots$ & $\cdots$ & $\ldots$ & 104 & 220 \\
\hline Percenta & e of & siti & & $\cdots$ & $\cdots$ & 85 & 0 \\
\hline
\end{tabular}

The findings of the cases investigated therefore furnish 85 per cent. positives out of 104 tuberculous subjects. As none of the controls that have been examined reacted positively to the test, it may be justifiable to regard the test as specific, and where a reaction is provoked a diagnosis may be safely pronounced, not only that the disease is present, but also that the lesion is in an active condition. Here, as in the Wassermann test, a negative finding is significant, though inconclusive.

The non-specific reaction which other observers bave found was due, we venture to suggest, to the presence of lipoids in their antigen and, in part, also to the tested serums being insufficiently heated. Even with our delipoidal antigen we have found it necessary, in order tc avoid a false reaction, to heat the serums for at least two full hours at $55^{\circ} \mathrm{C}$., the usual inactivation for half an hour at this temperature being, in our experience, inadequate for the purpose. Thirty of our positive serums were taken at random for quantitative estimation; in 13 the complement fixed was over 8 M.H.D.; in 7, between 6 and 8 M.H.D.; and in 10 between 4 and 6 M.H.D. The reaction here obtained is, on the whole, more pronounced than has elsewhere been recorded, and this we take to be due to the nature of our antigen, which, being free from lipoids, is more easily emuisified and consequently more favourable to interaction with its antibody.

This investigation is the outcome of the work which one of us is at present conducting on lipoid.free antigens, bacterial and otherwise, in vivo and in vitro, as means of diagnosis and treatment, and owes its inception primarily to the initiation by Professor James Ritchie of the study of the antigenic properties of lipoids. To him, for this and other valuable suggestions, we wish here to record our indebtedness. We would like also to thank Miss FitzGerald for kindness in supplying us with some of the Wassermann serums.

REFERENCES.

1 Wassermann: Deut. med. Woch., 1906, Bd. xxxii, S. 745. ${ }^{2}$ Nesfield: Lancet. 1910, ii, p. 1875. 3 Emery: Ibid., 1911, i. p. 485. 4 Dudgeon: Ibid., 1913, i, p. 19. Inman: Tbid, 1914, i, p. 1446. McIntosh an Fiddes. Ibid., 1914, i1, p. 485. it plete bibliography on the 8 Wang: Journ. Path and Bact.. 1919, vol x xiil. 9 Browning and Mackenzie: Diagnosis and Treatment of Syphilis. London, 1911. 10 Donald : Lancet, 1912, i, p.1752; ibid., 1915, ii, p. 1243 ; ibid., 1916, ii, p. 423.

\section{WILL THE USE OF SCOPOLAMINE-MORPHINE IN LABOUR HELP TO IMPROVE THE BIR'TH-RA'TE?}

BY

\section{W. OSBORNE GREENIWOOD, M.D.LEEDS, B.S.LOND.}

No one will gainsay that the present condition of the birth-rate is largely due to the express intentions of parents to limit their fanilies. Sir Arthur Newsholme says "all the facts point to the conclusion that volitional limitation of the family is the chief and vastly predominant cause of the decline in the birth-rate which is taking place in so many countries." Doubleday's hypothesis as to the influence of increased nutrition is at least so problematical as to be negligible, and Sir A. Newsholme discounts the theory of the inverse relationship between cerebral development and the capacity to procreate. We are mainly concerned, then, with the volitional element, and a rough classification of the grounds on which this is done 
will help us to obtain a better perspective of the subject. We may therefore make the following broad grouping:

1. The love of luxury and ease, an attitude which may be described as a kind of passive resistance.

2. The desire to have only as many children as can be well provided for and adequately educated beyond the " starting-point" the parents had.

3. Eugenic grounds.

4. Fear of the actual parturition.

5. To these may be added another that is not imme diately voluntary, but which will have a considerable influence in the near future. The increased prevalence of syphilis and gonorrhoea will cause a marked proportion of sterility.

As there can be no profitable discussion with passive resistance, and compulsion cannot be used, Group 1 may be dismissed. Moral suasion has been tried and has failed. Whatever one's broad opinion of Group 2 may be, it has at least some laudable basis. Regarding Group 3, it is doubtful whether there are more than a few hundreds in the whole country who limit their families on eugenic grounds alone. Although Group 5 is a purely medical concern, it will probably be long before the ravages wrought by venereal disease can be anything like repaired, and this group therefore furnishes an additional reason for addressing ourselves to the problem. Thus it is with Group 4 that this article will mainly deal, for the first three are entirely outside the scope of our art. 'The groups must not, however, be regarded as being distinct to the exclusion of all other considerations. Probably all will overlap one or more other groups, so that those who advance 4 as their main reason for refusing maternity will perhaps also be swayed by the reason under 2 .

The task of grappling with such a problem is formidable enough almost to make the nation shrink from facing it. On the other hand, we have done so much during these last few years that it is quite conceivable we may be in the right temper to overcome yet another obstacle.

For the practical purposes of this discussion, fear of the actual parturition is in the hands of the medical profession. The report of the late commission on the declining birth-rate states: "It is in the interests of the State as far as is practicable to remove all conditions -physical, economic, or social-which make parenthood an almost intolerable burden, especially on the mother." And, again, speaking of the fear of parturition, it says: "They (that is, women) may be assured that medical knowledge and skill can so relieve travail that it can be made at least bearable."

This fear of parturition is a very potent factor in the decline of the birth-rate as any one who goes to the trouble of inquiring will very quickly discover. The reason is simple. In no civilized nation can parturition be regarded as a "normal and physiological process." It is an event looked forward to with misgiving, and, moreover, fraught with tremendous pathological possibilities. My thesis now is that few labours can in any sense be called normal, and although this may not be expressed in exact terminology by women, it is the knowledge of the fact itself that has given rise to so widespread a fear of parturition. The accompanying and inevitable pain is the factor that appeals to them -hence the fear. It is certain we have hitherto failed to appreciate how general is this fear and what vast numbers are refusing maternity on this plea alone or nearly so.

It has often been said that parturition is not nearly as bad or dangerous as an acute attack of renal colic or appendicitis. This is no doubt partially true, but I have just interviewed a patient whose first words were to tell me her first labour lasted forty agonizing houis, at the end of which time she was grateful for the application of forceps without chloroform. This is far from being an isolated case in my experience, and it is this that is making women take advantage of the knowledge of contraceptives. Even if we admit parturition to be more bearable than some acute diseases the comparison is faulty, for, in the present state of our knowledge we must usually submit to such an attack as inevitable; nor is the patient aware of the impending ofdeal before its onset; there is nothing deliberate or voluntary about. it. It is here therefore, the supposed analogy and the comfort it is intended to give completely fail. With the present knowledge of contraceptires among even the poorest people, pregnancy, with its resulting labour, is a purely voluntary condition in a large percentage of cases. Not. even the most Spartan would deliberately invite acute cholelithiasis; considering the pathological character of a large number of labours, can we wonder that women who have a knowledge of its prevention are only too ready to use it? Therefore the point I have to urge is that if we have a means at our disposal of dispelling this fear of parturition we shall have gone far towards arresting the present alarming decline in the birth-rate.

It is only natural that the profession before discarding the time-honoured administration of chloroform in favou of scopolamine-morphine, and so allowing a far more extended use of a method of relieving the pains of labour, should be satisfied as to the safety of the supplanting method. In spite of the adverse criticism of a few eminent obstetricians, the verdict of a very large number who have used it fairly is that it is all it claims to be if administered with reasonable care and skill. But it is quite true that it demands time, and probably relatively few practitioners will be prepared to devote this time to it.

It is not possible to discuss fully the question of safety at present-I have done this exhaustively elsewhere following remarks must suftice. In a series of over 400 cases the stillbirths have been under 2 per cent., as against a general average of $2 \frac{1}{2}$ per cent. This represents a reduction of one-tifth in stillbirths, or 20 per cent. These stillbirths included such complications as premature detachment of the placenta, a difficult breech presentation with considerable delay of the head, another breech presentation with a large hydrocephalus which necessitated perforation, one macerated fetus, and the like. On the other hand, among the successes may be mentioned a Caesarean section, some twenty-five cases of severe albuminuria in which every child is alive (one mother was a primipara aged 49), and a large number of premature labours, spontaneous and induced. This is a record which no amount of theoretical criticism can destroy, and in particular the absence of ill effects on premature children is instructive and suggestive. One patient had had.two stillborn children before, in neither instance was scopolamine-morphine administered; the third child was boin under scopolamine-morphine and is alive and well. Several others have had oue stillborn child, while the second and third, under scopolamine-morphine, are alive and well. These cases emphasize the contention that the method is safe if overdosing be avoided. All the foregoing is amply borne out by Dr. Cecil Webb.Jolnnson in his book Twilight Sleep in the East, and it may now bo accepted as proved that the method is safe.

Thus far, then, we have reached the conclusions that the birth-rate in this country is in a very serious con dition ; that one potent factor is the fear among women of the actual labour; that this fear is by no means baseless, but has its origin in the pain and undoubted pathological character of the majority of labours; that the use of scopolamine-morphine entirely abolishes this fear, and has no counterbalancing evil results.

I must now draw attention to a significant fact. Of my own cases at least 7 per cent. were induced to submit to that particular pregnancy by the knowledge that they could have the labour conducted under scopolaminemorphine. At first sight this may not seem to be a great many, but on the modest assumption that it were possible for a million potential mothers to be assured of this treatment, we should have an increase of 70,000 births. The true percentage is in all probability greater than this, but is not even this worth an effort and a-sacrifice?

The question is, How is this end to be attained Coercion in a matter of this kind cannot be applied to the profession. Many cannot afford the extra time demanded for the administration of scopolamine-morphine; many have not the inclination; many of the poorer people could not pay the increased fee which every doctor would riglitly consider his due. Is there no solution of the difficulty? I believe a great majority of the profession would be glad to be rid of their maternity work, either theause of their distaste for it or because it interferes seriously with other work. If this is "so, and the question of the birth-rate is so vital to the country, why cannot the State bestir itself and take over this work in the national interest? They would get those who are deeply interested in the work and 
who are prepared to be expert in it. The results would justify their venture. Public health work is for all intents and purposes a State institution now; there has been some talk of taking over the hospitals (a much more diff. cult and perilous undertaking). We spend an enormous sum every year on hospitals or homes for incurables and on asylums for maintaining thousands upon thousands of hopeless lunatics. It is not suggested these should all be destroyed, though many thoughtful people have strong opinions on the subject. But if all this expenditure on perfectly useless life is considered legitimate, how much more legitimate would be an expenditure on the production of new life in the shape of an increased birth-rate?

I do not propose any elaborate scheme but merely an outline which may serve as a basis for discussion. Only the matter ought to be faced now, and not allowed to drift into another generation. First of all, we cannot admit any class distinction; rich and poor must equally feel they can have the advantage of scopolamine-morphine if they wish, so that we may hold out the inducement to all. To the large number who have refused maternity solely or mainly on account of the ordeal we may then say, "Your objection has been overcome, and you may now enter on pregnancy without the least fear."

The scheme in view would be the establishment in all large towns, in some very quiet part, and perhaps in certain other centres, of a combined midwifery hospital and home. Half, or some such proportion, of the beds could be reserved for those who could well afford to pay adequate fees, the remainder for those who perhaps could not afford any fee. It might even be practicable to have an intermediate grading. At all events the income from the one part would go largely towards maintaining the whole institution, and the burden on the State would, I venture to think, not be so great after all. The patients in the one part would have a bedroom each where the labour would be conducted. There would be one or more dining. rooms, as needed, common to this part. The others would be in rooms each of which would accommodate four to half a dozen beds, and to each of which would be attached one small lying-in room where the labour would take place. As for staff, one nurse can quite easily and efficiently attend to two patients in the better-to-do section if they are in contiguous rooms, an extra fee being charged if a patient preferred a nurse exclusively. In the small ward. rooms a nurse could easily manage one with some additional belp from a probationer. There would be a super. intendent obstetrician with assistants, the number of whom would be governed by the size of the institution. The success of it all would depend upon the enthusiasm of the staff, ana only those in sympathy with the work would undertake it. This would be a very different matter from public opinion trying to coerce every practitioner into using scopolamine morphine regardless of his individual objections, which might be perfectly valid.

I believe any Minister who had the courage to initiate and carry out some such scheme would deserve more than ever the country could repay him. The field is white unto harvest, only the implements and the reapers are needed.

REFimRENOEs.

1 The Declining Birth-rate. p. 33. (New Tracts for the Times.) $\mathrm{By}$ Sir A. Newsholme. K.C.B., M.D. 2 The Declining Birth-rate (Report Semiercosis during Labour. Oxford Modical Pross.

\section{THE CURE OF MULTIPLE WARTS ON THE FACE. \\ By CHARLES IND, M.D. \\ SITTINGBOURNE.}

THE removal of these tiny growths, judging by what I have witnessed, is often very difficult.

A recent patient's troubles have been the means of m devising a plan, a combination of two methods suggested sopsirately by other dermatologists, which seems to give a spoedy and admirable result.

A man, aged 35, had had the warts for eleven years. He had seborrhoes sicce of the scalp, and suffered from an extrem grade of seborrhoea oleosa of the body and face; the latter I consider not unimportant as far as the etiology of the warts is concerned.
The warts were of the variety known as verruca plans juvenilis (Stelwagon), tiny roundish bodies situated on the forehead and closely' set, especially as they neared the hair border. On tha forehead there were about ninety at least There were several dozens also on the scalp anteriorly. They -were all of the above variety. One or two increased in size, and rarely two or three would coslesce; but in the main the remained discrete. Those on the scalp were yellowish and slightly vascular, whilst those on the forehead were pale and rounded, not very easily seen unless looked for sideways.

For the whole eleven years the patient hod For the whole eleven years the patient had had treatment by dermatologists and doctors, but the number of warts did not show signs of diminishing. Internally he had had lime, thyroid extract, magnesium sulphate, and arsenic, also citric and other acids. He had also undergone electrolysis, and had had ionization with magnesium sulphate, and also with sodium salicylate but without any result, good or bad. Locally, nitric acid had been used, and had scarred him badly. Glacial acetic acid and trichloracetic acid had also been used. The warts were de stroyed by these methods and did not recur, but usually more appeared later near the site of local treatment.

I'he various spirit-soaps, and lotions of resorcin, sulphur, and mercury perchloride were of no use; ointments of salicylic acid and sulphur gave extremely bad results, and the patient refused to go on with them. Salicylic plaster seemed of some service, but it is unsightly and attracts attention.

Acting on the belief that warts are infectious the patient wore a removable lining to his hat, which was changed each day, and the warts were simply cut off by a sharp instrument; results were not very satisfactory and recurrence frequently followed.

Stelwagon ${ }^{1}$ recommends the use of a saturated alcoholic solution of salicylic acid, but says that it often fails to cure. By itself it did fail; but followed by abscission it was surprisingly effective. The warts and skin around were painted three times a day for one day with this liquid. On the following morning they were cut off by $a$ flat sharp steel instrument, bevelled on one side only; this passes freely over the healthy skin, but when it comes to the wart cuts it off, leaving a slightly bleeding point. The surface is painted at once with the salicylic solution and twice more later during the same day, three times in all. This turns the little red points to a brownish-black colour, tiny scabs form which are allowed to drop off, taking about a week to do so, and leaving a perfectly clear healthy skin. The forehead is bathed with pure alcohol once a day until the scabs have all dropped off.

1. A razor is no use, a sharp flat instrument pushed over the skin is necessary.

2. Paint three times the first day and after abscission three times on the second.

3. There is neither pain nor scarring.

4. Sepsis does not occur.

5. The treatment is useless for larger warts.

6. The use of the salicylic solution prevents pain when the warts are cut off and recurrence afterwards.

REFERENCF.
1 Stelwagon : Diseases of Skin, 1902 edition, p. 522.

\section{(troonian Pectures}

THE SIGNIFICANCE OF THE CEREBRAL CORTEX.

Delivered before the Royal College of Physicians of LONDON, JuNe, 1919.

G. ELLIOT SMITH, M.A., M.D., F.R.C.P., F.R.S., PROFEGSOR OF ANATOMT, UNIVERGITY OF MANCHESTER.

LECTURE IV.

(Abstract.)

THE conditions revealed in the earliest fossil reptiles that have definitely taken the line of development leading toward mammals enable us to draw the inference that the hypopallium (neostriatum) and the neopallium came into existence simultaneously. But in the ancestors of the reptiles at present living the new cortex consisted mainly of hypopallium, whereas mammals cultivated both the new cortical formations. When the hypopallium, bulging into the lateral venticle, filled up the limited space available in the reptilian brain progress in cerebral development was brought to a sudden stop. In mammals, however, the noopallium, lying upon the surface of the hemisphere, was 